\title{
Publish or and perish: A urological perspective on predatory publications
}

Michael Di Lena; J. Curtis Nickel

Department of Urology, Queen’s University, Kingston, ON, Canada

Cite as: Can Urol Assoc J 2018 April 6; Epub ahead of print. http://dx.doi.org/10.5489/cuaj.4987

Published online April 6, 2018

$* * *$

\section{Abstract}

Introduction: It is an accepted axiom that academics must publish to be considered successful. Open-source journals are quickly gaining traction in the scientific community as an effective way to disseminate important research. The open-access movement includes many successful, well-respected operations, but has also spawned a plethora of journals, some predatory and others that appear to be amateurish academic traps. We provide a first look at open-source journals, both reputable and predatory, specifically pertaining to urology.

Methods: A review of the email inbox of a single academic urologist was examined for journal article solicitations over a four-month span. Journals were excluded if they did not pertain to urology. Journals were analyzed according to journal-centred metrics ( $\mathrm{H}$ index, number of documents published, total citations, and number of citations per document) over one publishing year (2015).

Results: A total of 32 journals contacting a single academic urologist were included in this review. The majority of journals originated from North America (84.3\%) with a mean cost of $\$ 1567$ CAD. Of the 32 journals, only seven were listed on reputable databases. Of these journals, analysis of journal-specific metrics showed, on average, a journal $\mathrm{H}$ index of 6.71, total documents published over one year of 66.14, and number of citations per document of 0.59 . Some publications were found to make false claims of listing in vetted academic databases.

Conclusions: Choices for open-source journal publication are rapidly increasing in the field of urology. They are not all created equal. Publication in many of these journals will increase the risk of seeing academic careers perish rather than flourish. 


\section{Introduction}

In the current academic landscape, it is an accepted axiom that academics must publish to be considered successful. At many academic centres research is a significant factor in promotion, recognition and renumeration. This environment creates a situations where researchers feel incredible pressure to publish and and do so often. Quite understandably, with the labour and dedication put towards their work, academics want to ensure the publications reach a significant audience.

Although open source journals were not initially fully embraced by the academic community, its popularity has quickly grown. By 2011, 11\% of the world's articles were being published in fully open-access journals ${ }^{1,2}$. Open source journals have continued to become an increasingly attractive means of publication. As of March 2016, the Directory of Open Access Journals, a well recognized index of current open source journals, has been adding titles at a net rate of 6 titles per day, with 540 journals added over the quarter marking its highest growth rate since its inception ${ }^{1}$.

Initially the goals of these journals were quite idealistic as they inspired to change academic publishing for the better, lower costs, and expanded worldwide access to the latest research. The open access paradigm is based on the assumption that research findings, resulting from public-funded studies, should be freely available online ${ }^{2}$. To their credit, the open-access movement has spawned many successful, well-respected operations. PLOS ONE, for example, which charges a fee of US\$1,350 for authors in middle- and high-income countries, has seen the number of articles it publishes leap from 138 in 2006 to 23,464 last year, making it the world's largest scientific journal ${ }^{3}$. Unfortunately, the policing of these journals is difficult and quality are wide ranging when it comes to distribution and scientific impact. Predatory publishers have quickly infiltrated the open source movement whose aim to con researchers and ultimately make profits.

Given the current publishing landscape, the challenge for researchers is to work out when journal solicitation comes from a credible publisher ${ }^{5}$. Initiatives exist to make authors aware of these publishers. This includes Beall's List, created by a University of Colorado librarian Jefferey Beall who lists "potential, possible, or probable” predatory publishers ${ }^{6}$ and the Urology Green List ${ }^{7}$. Unfortunately, there are still many which have not yet been identified and continues to be quite difficult to distinguish between credible and predatory.

We provide a first look at open source journals, both reputable and predatory, specifically pertaining to Urology with aims to bring awareness to the growing prevalence of predatory publishing. 


\section{Methods}

\section{Study design and measures}

The email inbox of a single academic urologist was examined for journal article solicitations over a four month span (September - December 2016). Only English speaking journals and journals pertaining to Urology were included in the study.

Of the journals who solicited publications, country of origin, year of journal creation, cost per publication, number of editorial board offers were collected. Additionally, journals were analyzed according to journal centred metrics including $\mathrm{H}$ index, number of documents published, total citations, and number of citations per document over one publishing year (2015).

Journal metrics were obtained from reputable indexing sources including the Journal Citation Reports (JCR) ${ }^{9}$, Scimago Journal Rankings (SJR) ${ }^{10}$, and Directory of Open Access Journals (DOAJ) ${ }^{11}$. To be indexed by either the JCR, SJR or the DOAJ, journals must meet certain standards of quality including ethical publishing practices and in the case of the DOAJ and SCR, fully open access. Additionally, publishers of the solicited journals were also cross referenced to Beall's list to identify if any were found on his known or suspected predatory publishers list.

\section{Results}

\section{Journal demographics}

A total of thirty-two journals contacting a single academic urologist were included in this review. Table 1 lists the demographics of the solicited journals. The majority of journal publishers originated from the United States (84.3\%). Additionally, mean listed cost of publication in these journals was $\$ 1567$ CAN (+/- 613). The majority of the journals were created within the past 7 years with the largest number created after 2014 (46.8\%). Within the request for article submission, 5 journals also offered editorial board placement without credential or CV request.

\section{Journal indexing}

As seen in Figure 1, the solicited journals were cross referenced to credible indexing directories (JCR, DOAJ and SCR). 6 of the 32 journals (18.8\%) were listed in the SCR directory, 4 of the 32 journals (12.5\%) were listed in the DOAJ and 1 of the 32 journals (3.1\%) were listed in the JCR. In total, 7 of 32 journals were found on at least one indexing website. It was interesting to note that 28 of 32 journals (87.5\%) made reference to indexing either on the journal website or via email correspondence.

Journal publishers were also identified and cross referenced to Beall's list of presumed predatory publishers (Figure 2). Of the 32 journals which contacted our academic urologist, 29 requests were from distinct publishers. Upon review, 20 of the 29 publishers (68.9\%) were identified to be suspected of predatory practices on Beall's List. 


\section{Journal-specific metrics}

Table 2 lists the journal centred metrics over one publishing year (2015). Of the 32 journals which contacted the academic urologist, a total of only 7 journals had indexed information from the indexing databases (SCJ, DOAJ, and JCR). Analysis of journal specific metrics for these 7 journals showed and mean journal $\mathrm{H}$ index of 6.71. The mean number of documents published per year was found to be 66.14 with total yearly citations amounting to 96.86 . Additionally, the mean number of citations per document were 0.59 .

\section{Discussion}

The analysis of our collected email journal solicitations showed that the vast majority of solicited journals were not found on credible indexing databases with only 7 of the 32 solicitations identified (21.9\%). Furthermore of the 29 distinct publishers, 20 are suspected of predatory publishing practices as per Beall's List.

The mean listed cost of publication in the journals was found to be \$1567 CAN (+/- 613) with the majority of the journals created within the past 7 years. Analysis of the journal specific metrics revealed a wide disparity between journals with an average $\mathrm{H}$ index of 6.71 and citations per article document of 0.59. For reference, in the same publishing year (2015) the Journal of Urology H-index was 211 with 1270 documents published and an average of 4.38 citations per document. These data support the presumption that the majority of these solicited journals lack credibility and if granted publication are unlikely to reach a significant audience despite the significant publication fee. It is important to note that these journal metric data are solely from those indexed which increasingly favourably skews the results. The other journals could not found on any of the indexing databases, strongly suggesting a predatory publication. Journals not found on the indexing databases were also universally found on Beals list which further supports this presumption. Although not formally indexed, this did not deter the publishers to make claims of both database indexing and high impact factor and $h$ indexes.

With the root of the open source movement originating from a noble cause, it is easy to ask how these journals made such inroads into academia. A large part is secondary to flimsy or at times non existent editing standards, mainly from journals driven solely by profit. In 2013, journalist John Bohannon revealed the problems of the predatory 'peer reviewed' system. His completely fabricated and intentionally flawed research paper was accepted for publication by 157 of 304 open-access journals to which it was submitted ${ }^{12}$. The editorial boards of these journals are often falsified with academics often unwittingly listed with no affiliation to the journal or under a constant promise of “coming soon”. In our experience, 5 of 32 journals offered placement on their editorial board with no request of CV or credentials. This practice is unfortunately quite commonplace. Pisanski and colleagues exposed the illegitimacy of these editorial boards in 2015 when their fictitious scientist was accepted to the editorial board of 48 of 360 journals ${ }^{13}$. It would be naive to ignore however a second underlying issue. These predatory publishers are also exploiting a market inefficiency that exists in academia. Researchers continue to feel incred- 
ible pressure to publish and in a system that uses quantity as a proxy for quality there, at times, may be little incentive to determine journal legitimacy. An article by the PLoS Medicine Editors found that the main reason of the researchers' decision to publish in specific journals closely relates to funds assigned and to career advancement ${ }^{14}$. Furthermore, in many academic centres, at least one peer reviewed publication is a prerequisite for gaining a $\mathrm{PhD}$. Although efforts are being made in recognizing publications made in high impact journals, until the underling drivers of this problem are addressed, it is likely that predatory journals will continue to successfully exist.

In this study, we have not included the names of the journals. We can attribute this reason partially to the fact that predatory publishers often strategically name their publication similar to reputable titles in an attempt to confuse and trick researchers. This practice is so commonplace that Beall specifically identified "Hijacked Journals," which identified predatory/fake journals meant to look and sound like the titles of legitimate ones ${ }^{15}$. The problem is much more prevalent than the journals discussed here. Ultimately the question remains, how should academics proceed?

By no means do we claim that open source journals who solicit submissions are predatory however, in our experience, it should justifiably elicit a cautious progression when considering scholarship publication. Fortunately, the landscape is not completely bare as there are some groups whose goal is to identify publishers who may be predatory in nature. One such person is librarian Jeffrey Beall who created a widely used black list consisted of journals that in his opinion exploited researchers and failed to meet standards of scholars publishing titled Scholarly Open Access. Beall regularly receives e-mails from researchers unhappy about their experiences with some open-access journals whether it was because of concerns of their peer review process, hidden feeds after acceptance of paper publication, or concerns of the legitimacy of the paper altogether. Unfortunately for reasons currently unknown, Beall has since removed his list in January 2017. Thankfully, Dr. Henry Woo has developed an resource dedicated to the field of Urology titled the Urology Green List. As opposed to identifying predatory publishers, the Urology Green List focus remains on identifying credible journals, both subscription and open access, where it is considered safe for the urological community to send their research for publication.

\section{Conclusion}

Choices for open source journal publication are rapidly increasing in the field of Urology. They are not however all created equal. There remains a haze of uncertainty when it comes to publication in open access journals. Ultimately, like much in medicine, one must use their clinical judgement to distinguish between reputable and predatory publishers. There remains quite successful and powerful open access journals and to outright ignore these would be a shame and unnecessarily punitive. We are suggesting that there be appropriate due diligence in establishing the authenticity of the journal. Consultation with a colleague or medical librarian, when in doubt, can clarify the status of an OA journal. Unfortunately if not careful, publication 
in many of these journals will increase the risk of seeing academic careers perish rather than flourish.

\section{References}

1. Poltronieri E, Bravo E, Curti $\mathrm{M}$ et al. Open access publishing trend analysis: statistics beyond the perception. Information Research. 2016;2: 712.

2. Suber P. Open access overview. 2016. http://legacy.earlham.edu/ peters/fos/overview.htm. Accessed February 122017.

3. The PLoS Medicine Editors. The impact factor game. PLoS Medicine. 2016;6: 291.

4. Pierce GN. Is open-access publishing the wave of the future in science? Canadian Journal of Physiology and Pharmacology. 2016; 92: 5.

5. Broome ME. Open access publishing: a disruptive innovation. Nursing Outlook. 2014;62: 69-71.

6. Beall J. Beall's List: Potential, possible, or probable predatory scholarly open-access publishers. http://beallslist.weebly.com. Accessed December 2016.

7. Urology Green List. 2016.https://urologygreenlist.wordpress.com/. Accessed March 5 2016.

8. Wicherts JM. Peer review quality and transparency of the peer-review process in open access and subscription journals. PloS one. 2016;11: 1

9. Journal Citation Reports. 2016. https://jcr.incites.thomsonreuters.com. Accessed December 62016.

10. SJR. Scimago Journal \& Country Rank. 2016. http://www.scimagojr.com/journalrank.php. Accessed December 62016.

11. DOAJ. Directory of Open Access Journals. 2016. https://doaj.org/bestpractice. Accessed December 62016.

12. Bohannon J. Who's afraid of peer review. Science. 2013;342: 6154

13. Pisanski K, Sorokowski P, Kulczycki E et al. Predatory journals recruit fake editor. Nature. 2017;543: 481-483

14. The PLoS Medicine Editors. The Impact Factor Game. PLoS Med. 2016;6: 291

15. Dadkhah M, Borchardt G. Hijacked Journals: An Emerging Challenge for Scholarly Publishing. Aesthet Surg J. 2016;36:739-41 


\section{Figures and Tables}

Fig.1. Solicited journals listed and indexed in the Journal Citation Reports (JCR), Scimago Journal Rankings (SCR), and Directory of Open Access Journals ( DOAJ) $(\mathrm{n}=32)$.

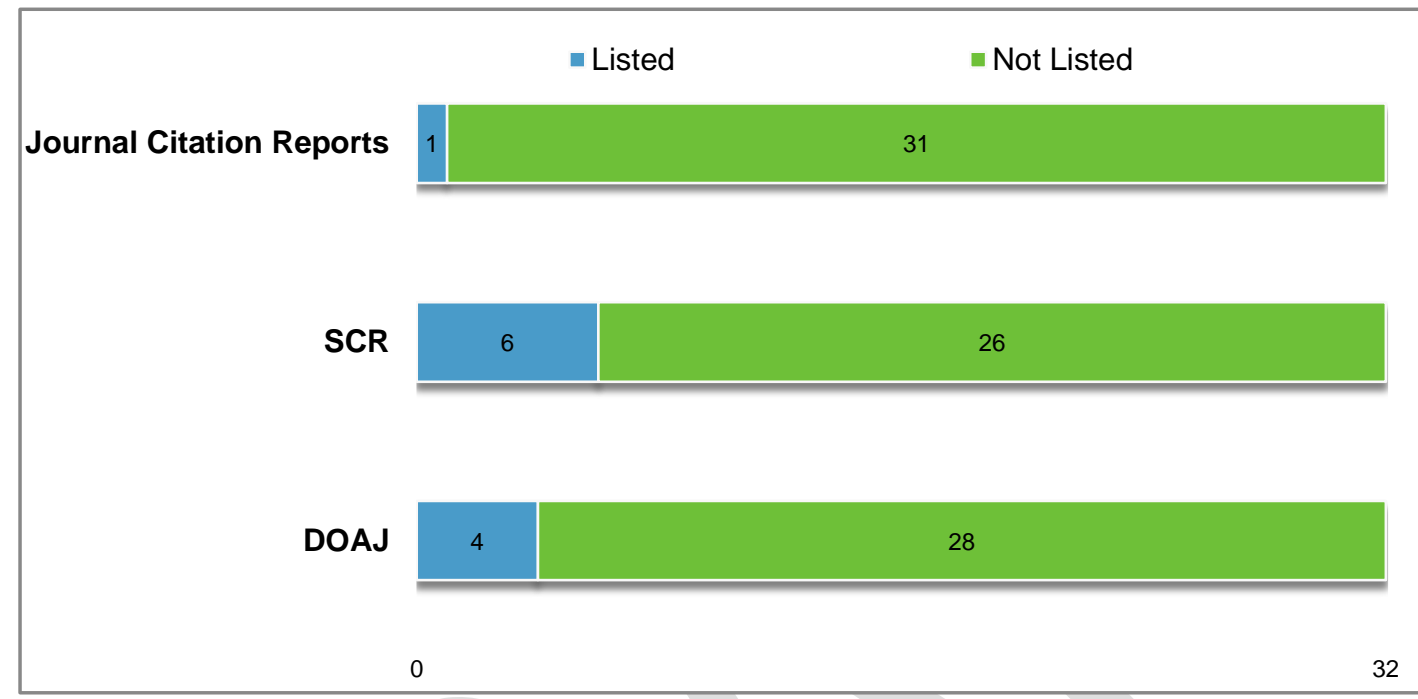

Fig. 2. Publishers of solicited journals listed in Bealls List (n=29).

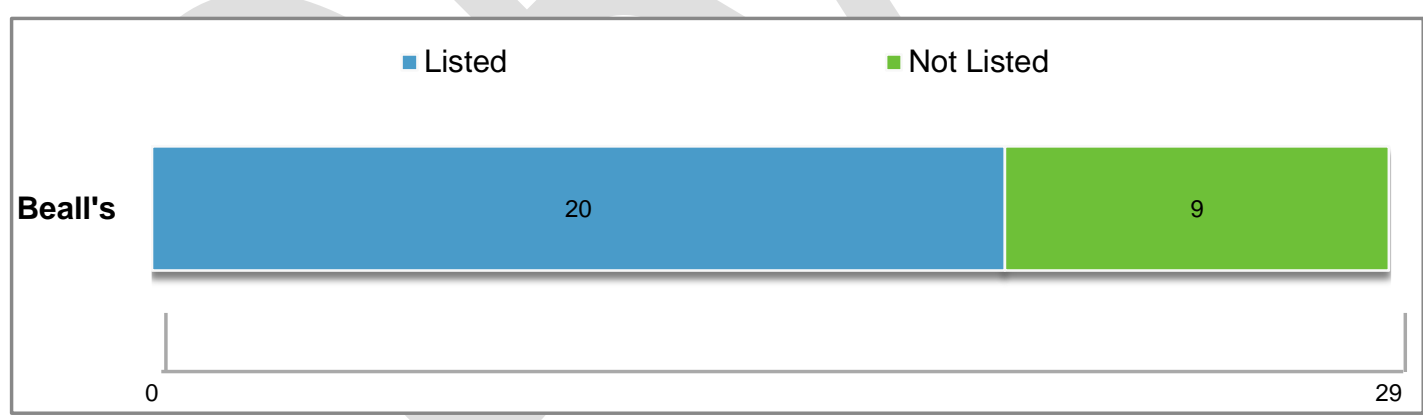




\begin{tabular}{|c|c|}
\hline \multicolumn{2}{|l|}{ Table 1. Overview of solicited journals (n=32) } \\
\hline & $\mathbf{n ~ ( \% )}$ \\
\hline Year of journal creation & $15(46.8)$ \\
\hline $2014+$ & $12(37.5)$ \\
\hline $2011-2014$ & $2(6.25)$ \\
\hline $2006-2010$ & $3(9.37)$ \\
\hline Not listed & $\$ 1567$ CAD \pm 613 \\
\hline Cost per journal publication & $27(84.3)$ \\
\hline Origin of journal & $5(15.7)$ \\
\hline U.S. & $5(15.7)$ \\
\hline Other & \\
\hline $\begin{array}{l}\text { Number of offers to be placed on } \\
\text { editorial board }\end{array}$ & \\
\hline
\end{tabular}

Table 2. Journal-specific metrics for indexed journals $(n=7)$

\begin{tabular}{|l|l|}
\hline H Index & $6.71 \pm 5.64$ \\
\hline $\begin{array}{l}\text { Total documents published over 1 year } \\
(2015)\end{array}$ & $66.14 \pm 38.9$ \\
\hline Total citations (2015) & $96.86 \pm 96.1$ \\
\hline Citations per document & $0.59 \pm 0.44$ \\
\hline
\end{tabular}

